\title{
Repair of Ventral Hernia by Pre-Peritoneal and Pre- Posterior Rectus Sheath Insertion of Prolene Mesh
}

Ashraf A Helmy, Gamal Ahmed Makhlouf* and Ragai Sobhi Hanna

Faculty of Medicine, Assiut University, Egypt

\begin{abstract}
Background: Early treatment of hernia is very important to reduce the risk of obstruction and or strangulation. Ventral hernias include umbilical, epigastric, and incisional hernias and represent $10-15 \%$ of all primary hernias. Conventionally, theses hernias are treated by suture repair with a substantial rate of recurrence and this increase the demand for a better technique of repair. There is no exact protocol or consensus on how the repair should be carried out.
\end{abstract}

Aim of work: To present a new surgical technique for ventral hernia repair with least recurrence rate.

Material and methods: This study was performed at a tertiary hospital and included 100 patients with uncomplicated ventral hernias and fit for surgery. Partial pre-peritoneal and partial subrectal insertion of prolene mesh was the new surgical technique done.

Results: The study included 58 females and 42 males. The mean BMI was 28.6. The mean defect size was 30.3 cm (range 9-64).

The mean operative time was 47.5 minutes (range 35- 62). The mean hospital stay was 2 days (range 2-4). Postoperative complications including wound infection (3 cases), seroma (7 cases) and hematoma (2 cases). Recurrence occurred in one case after 1 year. The efficacy rate was $98.75 \%$.

Conclusions: Pre-peritoneal and pre- posterior rectus sheath insertion of prolene mesh is a new surgical technique for ventral hernia repair with high efficacy and low recurrence rate.

Keywords: Ventral hernia; Insertion; Pre-peritoneal; Pre-posterior rectus sheath; Prolene mesh

\section{Introduction}

Early treatment of hernia is very important to reduce the risk of obstruction and or strangulation [1]. Ventral hernias include umbilical, epigastric, and incisional hernias and represent $10-15 \%$ of all primary hernias [2]. Conventionally theses hernias are treated by suture repair with a substantial rate of recurrence and this increase the demand for a better technique of repair [3]. There is no exact protocol or universal consensus on how the repair should be carried out.

There are many techniques but no one of them provide good long lasting result. The recurrence of hernia results in great psychological and financial trauma to the patient and increase the demand for developing better technique of repair [4].

Several studies have pointed out the superiority of mesh over sutures to avoid the recurrence $[5,6]$.

The aim of this study is to present a new surgical technique for ventral hernia repair with least recurrence rate.

\section{Materials and Methods}

This study was performed at Assiut University Hospital during 2 years period and included 100 patients with uncomplicated ventral hernias. All patients were subjected to history taking, physical examination, standard laboratory work up and Abdominal Ultrasonography.

\section{Inclusion criteria}

- All patients with ventral hernia.

\section{Exclusion criteria}

- Previous mesh implantation.

- Significant co morbidity.
- BMI more than $40 \mathrm{~kg} / \mathrm{m}^{2}$.

- Pregnant women.

- Contaminated abdominal cavity.

- Long term use of immunosuppressive agent.

\section{Preoperative preparation}

All patients were advised to have a preoperative shower with cleaning of the umbilicus. The patient receive single dose of cefuroxime at the induction of anesthesia either spinal or general.

Operative technique: The same surgical team, having adequate experience in hernia surgery, performed all the operations. A horizontal incision was made in case of umbilical or paraumblical hernia. Vertical incision was made in case of incisional hernias. The rectus sheath was exposed about one inch around the defect. The sac was opened, the content were identified and reduced into the peritoneal cavity after releasing of any adhesion then herniotomy was performed. Two vertical incisions were made in the most medial parts of the anterior rectus sheaths.

The rectus muscle was dissected from the posterior rectus sheath. The peritoneum in the midline was dissected from the linea alba for

*Corresponding author: Gamal Ahmed Makhlouf, MD, Assistant Professor of General Surgery, Faculty of Medicine Assiut University, Assiut 71515, Egypt, Tel: 01005506115; Fax: +20 88-2354130; E-mail: g_makhlouf@yahoo.com

Received April 26, 2017; Accepted May 24, 2017; Published May 31, 2017

Citation: Helmy AA, Makhlouf GA, Hanna RS (2017) Repair of Ventral Hernia by Pre-Peritoneal and Pre- Posterior Rectus Sheath Insertion of Prolene Mesh. Surgery Curr Res 7: 296. doi: 10.4172/2161-1076.1000296

Copyright: $\odot 2017$ Helmy AA, et al. This is an open-access article distributed under the terms of the Creative Commons Attribution License, which permits unrestricted use, distribution, and reproduction in any medium, provided the original author and source are credited. 
at least one inch above and below the hernial defect. This dissection created a space formed below by the posterior rectus sheath on either sides of the hernial sac and the peritoneum which underlies the linea alba.

In this space polypropylene mesh was placed in after adjusting its size from 2 to $3 \mathrm{~cm}$ more than the defect. The mesh was then fixed to the edge of the defect which was formed laterally by the anterior rectus sheaths and formed cranially and caudally by the linea alba. It was fixed firstly by 4 interrupted absorbable sutures then continuous all around suture was made between the edge of the defect and the mesh by polypropylene suture. This repair was tension free.

A suction drain was placed over the mesh and brough out through a separate incision. Skin edges were approximated by stitches. Drain were removed when the output stopped or less than $30 \mathrm{ml} / 24$ hours. Stitches were removed after 10 days. The patients were advised to wear abdominal binder for 3 months. Operative time, postoperative complications, hospital stay, and quality of life after surgery were assessed. The patients were followed up on a regular schedule at 2 weeks, 6 months, and 12 months post-operative (Figures 1-4).

Ethical consideration: Approval from medical ethical committee of Assiut Faculty of Medicine was taken. Each patient gave his/her written consent to participate in the study.

Statistical analysis: Statistical analysis was performed using statistical package for the social sciences (SPSS - version 20). Categorical variables were described by number and percent $(\mathrm{N}, \%)$, whereas continuous variables were described by mean and standard deviation (Mean, SD).

\section{Results}

The study included 100 patients with ventral hernia (the hernia was umbilical in 39 patients, paraumblical in 47 patients and incisional in 14 patients. Their demographic data are shown in Table 1 . The age ranged from 25 to 79 years with mean age of 45 years. The study included 58 females and 42 males. The mean BMI was $28.6 \mathrm{~kg} / \mathrm{m}^{2}$ (range 23.5-32.6). The mean defect size was $30.3 \mathrm{~cm}$ (range 9-64).

The predisposing factors were obesity, multiparity, chronic cough were found in 15 patients. The mean operative time was 47.5

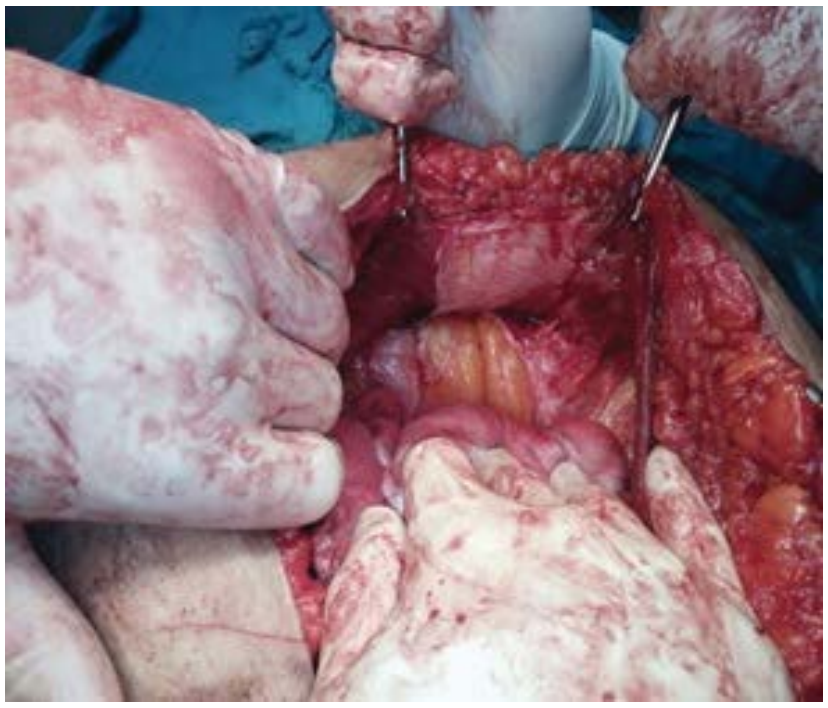

Figure 1: Separation of rectus muscle from the peritoneum.

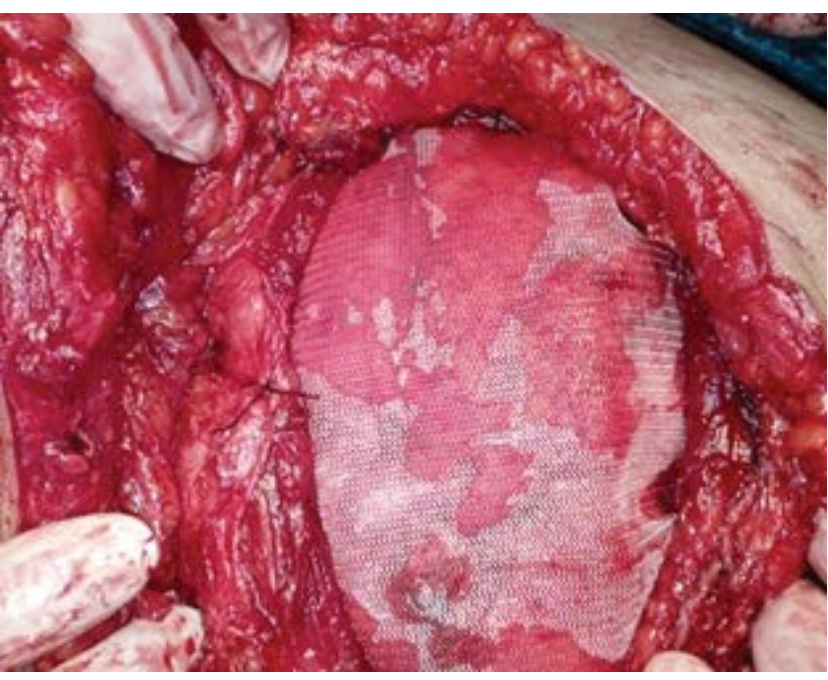

Figure 2: Prolene mesh was fixed by 4 stitches.

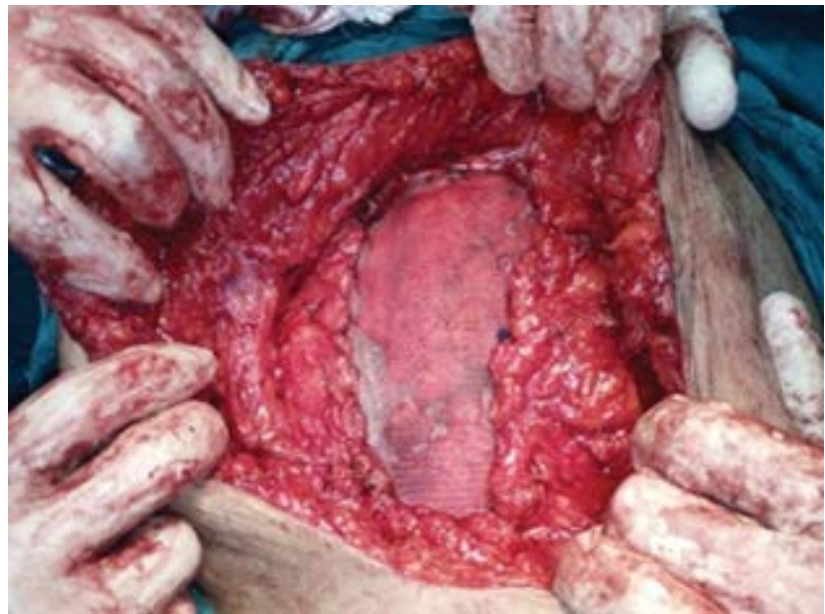

Figure 3: The prolene mesh was fixed by continous sutures all around.

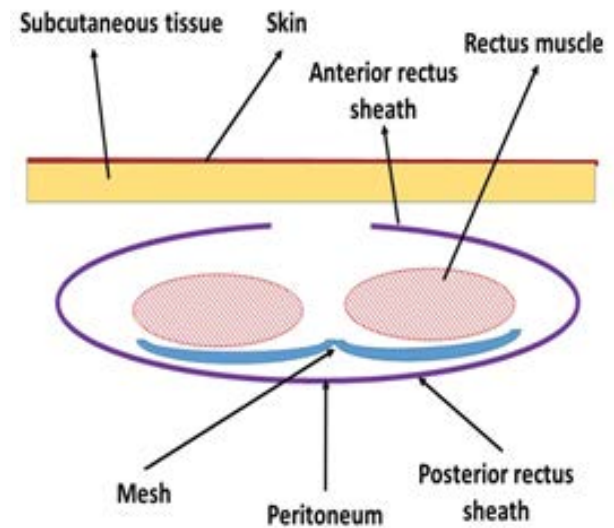

Figure 4: Schematic picture for the new surgical technique for ventral hernia repair. 


\begin{tabular}{|c|c|}
\hline Age (years) & \\
\hline Mean \pm SD & $45.0 \pm 9.1$ \\
\hline Range) & 25 to 79 \\
\hline \multicolumn{2}{|l|}{ Gender } \\
\hline Female & $58(58 \%)$ \\
\hline Male & $42(42 \%)$ \\
\hline \multicolumn{2}{|c|}{ Body mass index (BMI) $\left(\mathrm{kg} / \mathrm{m}^{2}\right)$} \\
\hline Mean \pm SD & $28.6 \pm 2.7$ \\
\hline Range & $23.5-32.6$ \\
\hline \multicolumn{2}{|c|}{ Defect size $(\mathrm{cm})$} \\
\hline Mean \pm SD & $30.3 \pm 15.9$ \\
\hline Range & $9-64$ \\
\hline
\end{tabular}

Data were expressed as Mean \pm SD and range or as number and percentage. Total number (100 cases)

Table 1: Demographic data of the study group.

minutes (range 35-62). The mean hospital stay was 2 days (range 2-4). Postoperative complications including wound infection (3 cases), seroma ( 7 cases) and hematoma ( 2 cases). About 80 patients had complete follow up till 1 year postoperative and 20 patients have lost follow up (13 cases at 6 month post-operative, 7 cases at 1 year). Recurrence occurred in one case (out of 80 patient with regular follow up) after 1 year. This case with recurrence had early wound infection. There was no postoperative chronic pain and there was improvement in quality of life (Table 2)

\section{Discussion}

Among the common ventral hernias are the incisional and paraumbilical hernias constituting about $85 \%$ of ventral abdominal hernias [4]. The optimum treatment method for theses hernias is still under debate and there are no guidelines recommend the most appropriate treatment [7]. In the current study, the commonest type was paraumblical in $47 \%$ of patients, followed by umbilical in 39\% patients, and lastly incisional which occurred in $14 \%$. There was progress in different surgical options which included simple tissue repair, mesh and recently introduced laparoscopic repair technique [4].

The present study determines the efficacy of partial pre-peritoneal and partial subrectal insertion of prolene mesh in various types of ventral abdominal hernias. The mean operative time was 47.5 minutes (range 35- 62). The mean hospital stay was 2 days (range 2-4). Malik et al. in their study reported that the total operative time is reasonably less in mesh repair compared to suture repair (operative time was up to 40 minutes in 15 cases with mesh repair and 4 cases with suture repair; up to 60 minutes in 77 cases with mesh and 49 cases with suture repair; up to 90 minutes in 41 cases with mesh repair and 45 cases with suture repair) [4].

Malik et al. reported that 23 patients (22.77\%) (out of 101 cases with various ventral hernias operated by suture repair) developed recurrence while recurrence occurred in 10 patients (7.40\%) (out of 135) with mesh repair. This is consistent with various similar trials reporting superiority of mesh repair in terms of recurrence [8-10]. In the current study, recurrence occurred in one case after 1 year (1.25\%). Also, there was no postoperative chronic pain and there was improvement in quality of life in the present study. However, a study showed that long continued abdominal pain/discomfort in $14(13.86 \%)$ patients operated by suture repair versus $4(2.96 \%)$ in the mesh repaired patients. In the present study early postoperative complications included wound infection ( 3 cases), seroma ( 7 cases) and hematoma ( 2 cases). Similarly study seroma formation (12/135) and wound infection (11/135) were more frequent in mesh repair [4].

\begin{tabular}{|c|c|}
\hline Umbilical & 39 patients $(39 \%)$ \\
\hline Para-umblical & 47 patients $(47 \%)$ \\
\hline Incisional & 14 patients $(14 \%)$ \\
\hline The mean operative time (minutes) & $47.5 \pm 8.7$ \\
\hline Mean \pm SD & $35-62$ \\
\hline Range & $98.75 \%$ \\
\hline Efficacy rate of new procedure & 3 cases $(3 \%)$ \\
\hline Early and late complications & 7 cases $(7 \%)$ \\
\hline Wound infection & 2 cases $(2 \%)$ \\
\hline Seroma & 1 case $(1.25 \%)^{*}$ \\
\hline Hematoma & Recurrence \\
\hline
\end{tabular}

Data were expressed as Mean \pm SD and range or as number and percentage Total number (100 cases). *Patient who complete their follow up $(n=80)$

Table 2: Types of hernia, duration of surgery, and complications.

In a systematic review that included 2418 patients from six cohort studies, the overall infection rate for mesh hernioplasties was 5 percent [11]. There are conflicting data regarding whether the use of mesh during hernia repair results in a greater risk for infection than traditional repair without mesh. Following a primary, non-mesh suture repair the reported risk of wound infection ranges from 0 to 6 percent [12], while the risk of infection after a mesh repair ranges from 0.4 to 14 percent [13-16].

A randomized trial that included 93 patients comparing mesh or non-mesh repair for umbilical hernias reported increased rates of infection following mesh repair (28 versus 9 percent) [17].

\section{Conclusion}

Pre-peritoneal and pre- posterior rectus sheath insertion of prolene mesh is a new surgical technique for ventral hernia repair with high efficacy and low recurrence rate.

\section{References}

1. Mahadevan $V$ (2006) Anatomy of the anterior abdominal wall and groin Surgery 24: 220-254

2. Muschaweck U (2003) Umbilical and epigastric hernia repair. Surg Clin North Am 83: 1207-1221.

3. Hesselink VJ, Luijendijk RW, de Wilt JH, Heide R, Jeekel J (1993) An evaluation of risk factors in incisional hernia recurrence. Surg Gynecol Obstet 176: 228234

4. Malik AM, Jawaid A, Talpur AH, Laghari AA, Khan A (2008) Mesh versus nonmesh repair of ventral abdominal hernias. J Ayub Med Coll Abbottabad 20: 54 -56 .

5. Abdel-Baki NA, Bessa SS, Abdel-Razek AH (2007) Comparison of prosthetic mesh repair and tissue repair in the emergency management of incarcerated para-umbilical hernia: A prospective randomized study. Hernia 11: 163-167.

6. Winker MS, Gerharz E, Dietz UA (2008) Overview and evolving strategies of ventral hernia repair. Urologe A 47: 740-747.

7. Courtney CA, Lee AC, Wilson C, O'Dwyer PJ (2003) Ventral hernia repair: A study of current practice. Hernia 7: 44-46.

8. Sanjay P, Reid TD, Davies EL, Arumugam PJ, Woodward A (2005) Retrospective comparison of mesh and sutured repair for adult umbilical hernias. Hernia 9: 248-251.

9. Iannitti DA, Hope WW, Noroton HJ, Lincourt AE, Millikan K, et al. (2008) Tech nique and outcome of abdominal incisional hernia repair using a synthetic composite mesh: A report of 455 cases. J Am Coll Surg 206: 83-88.

10. Kingsnorth AN, Shahid MK, Valliatu AJ, Hadden RA, Porter CS (2008) Open onlay mesh repair for major abdominal wall hernias with selective use of components separation and fibrin sealant. World J Surg 32: 26-30. 
11. Mavros MN, Athanasiou S, Alexiou VG, Mitsikostas PK, Peppas G, et al. (2011) Risk factors for mesh related infections after hernia repair surgery: a meta analysis of cohort studies. World J Surg 35: 2389-2398.

12. Birolini C, Utiyama EM, Rodrigues AJ, Birolini D (2000) Elective colonic operation and prosthetic repair of incisional hernia: does contamination contraindicate abdominal wall prosthesis use? J Am Coll Surg 191: 366-372.

13. Petersen S, Henke G, Zimmermann L, Aumann G, Hellmich G, et al. (2004) Ventral rectus fascia closure on top of mesh hernia repair in the sublay technique. Plast Reconstr Surg 114: 1754 -1760.

14. Pierce RA, Spitler JA, Frisella MM, Matthews BD, Brunt LM (2007) Pooled data analysis of laparoscopic vs. open ventral hernia repair: 14 years of patient data accrual. Surg Endosc 21: 378-386.

15. Forbes SS, Eskicioglu C, McLeod RS, Okrainec A (2009) Meta-analysis of randomized controlled trials comparing open and laparoscopic ventral and incisional hernia repair with mesh. Br J Surg 96: 851-858.

16. Brown RH, Subramanian A, Hwang CS, Chang S, Awad SS (2013) Comparison of infectious complications with synthetic mesh in ventral hernia repair. Am J Surg 205: 182-187.

17. Korenkov M, Sauerland S, Arndt M, Bograd L, Neugebauer EA, et al. (2002) Randomized clinical trial of suture repair, polypropylene mesh or autodermal hernioplasty for incisional hernia. Br J Surg 89: 50-56. 